\title{
Design of Low Power CMOS Array and Tree Multiplier using DSM Technology
}

\author{
Chalamalla.Rajendra Prasad, B. Rajeshwari, Dayadi.Laksmaiah
}

\begin{abstract}
: currently days, improvement of digital gadgets has been advanced. The requirement for low-manage configuration is additionally turning into a noteworthy problem in superior computerized framework plan programs. A 4 piece CMOS Multiplier has one heart of the chip in dealing with framework structure it require low manipulate usage This paper complicated the multiplier plans of both Array and Tree in 90nm, 65nm, improvements. on this the real segment is CMOS multiplier in labored of adders which makes use of conventional Static CMOS (CSL) logic configuration fashion using the Deep Submicron innovation at various stock voltages. the key point of our mission is to consider the CMOS Array and Tree 4x4 Multipliers concerning Propagation delay, strength dissemination and Transistor check. the usage of CMOS 1 piece complete snake cell for low power is won and is actualized on Array and Tree multiplier and the consequences are investigated for stepped forward strength delay item. The circuit plan and reenactment is finished with MICROWIND tool
\end{abstract}

Keywords: Array Multipliers, Tree Multiplier Full adder, CMOS.

\section{INTRODUCTION}

The ultra low power can be implemented with the special rationale styles. The three maximum critical techniques to quantify the element of VLSI circuit is the location, manipulate dissemination and time delay. Multipliers are fundamental subsystems for chip, DSP, and implant frameworks with packages run from lower of to convolution neural systems. sadly, CMOS multipliers are structure with the aid of complex purpose CMOS circuits. It expends greater energy. ultimately, assessed CMOS multiplier circuit configuration has changed into a big research subject as of past due.

The CMOS multiplier module is applied to duplicate the channel coefficients with got info signals. A4 bit CMOS multiplier consting a touch vital squares: incomplete objects generation, fractional objects abatement and bring proliferate enlargement. Approximations could be exhibited in any of those squares. as an instance, truncation of the fragmentary gadgets is a nicely-perceived gauge strategy in which a part of the partial items aren't framed and the truncation technique is reduced with the help of appropriate treatment capacities. further methodologies rearrange the

Revised Manuscript Received on 16 September, 2019.

Chalamalla.Rajendra Prasad, Assistant professor, ECE Dept. VignanaBharathi Institute of Technology, Ghatkesar (Mdl.), Hyderabad, Telangana, India.

B.Rajeshwari, Assistant Professor, ECE Dept. VignanaBharathi Institute of Technology, Ghatkesar (Mdl.), Hyderabad, Telangana, India.

Dr. Dayadi.Laksmaiah, Professor, ECE Dept. VignanaBharathi Institute of Technology, Ghatkesar (Mdl.), Hyderabad, Telangana, India.

(email: laxmanrecw@gmail.com)

Dr.Sake. Pothalaiah, Professor, ECE Dept. VignanaBharathi Institute of Technology, Ghatkesar (Mdl.), Hyderabad, Telangana, India. fractional item lattice by making use of inexact $2 \times 2$ or four $\times$ four sub-multipliers

This paper is a have a look at of the go with the flow status of studies and practices in different orders of lowcontrol VLSI advancements.

The necessities to be happy by way of procedure advancements and gadget structures are surveyed simply as a few circuit configuration styles and plan techniques. The effect of the plan mechanization apparatuses is tested with an fantastic accentuation on physical shape and rationale aggregate pursued by way of a concise conversation of the impact of the framework definition, programming and calculations to the complete control skillability. creating semiconductor innovations and system structures are pointed out and the paper is finished up with the styles and studies subjects for what is to come back.

\section{PRESENT MODEL PAINTINGS}

Conventional Static Logic (CSL):

Everyday static CMOS intent is utilized in maximum excessive chip structures in VLSI packages. It entails bearing on NMOS pull-down and PMOS dismantle up systems to power ' 0 ' and ' 1 ' yields. The sorts of much less postponement and marvelous commotion fringe of this intent style in low strength and simple to shape and the opposite little bit of leeway of voltage scaling is against of strength static CMOS purpose style and length of MOS transistor which empowers low working voltage. The circuit define figure 1 include of 30 transistors to execute everyday static purpose fashion full snake. The largest correlation of dynamic and static fashion.Clock sign is applied to evaluate combinational CMOS cause circuit. Be that as it may, to simply understand the significance of the qualification, the peruser will need foundation on static motive.



Figure 1: CSL Logic Full adder

Published By:

Blue Eyes Intelligence Engineering

\& Sciences Publication 


\section{PROPOSED FULL ADDER MODEL WORK}

To decrease the power also a fresh out of the plastic new form with selective total of CMOS transistors was proposed in CMOS 10T-complete snake rendition. in this total snake model is executed utilizing an altered XNOR module utilizing four MOS transistor, each other XNOR module which wound up used in another model and one multiplexer. on this proposed adaptation customary static presence of mind total snake consisting10transistors.in this proposed circuit a fresh out of the box new two XNOR door which named baseless XNOR, select XNOR and one multiplexer are used.An endeavor is made to constrain swing at interconnect hubs from achieving VDD, yet in the yield amazing visit is reestablished to the general good judgment, high and low in light of the corresponding rationale and along these lines the power might be shop.

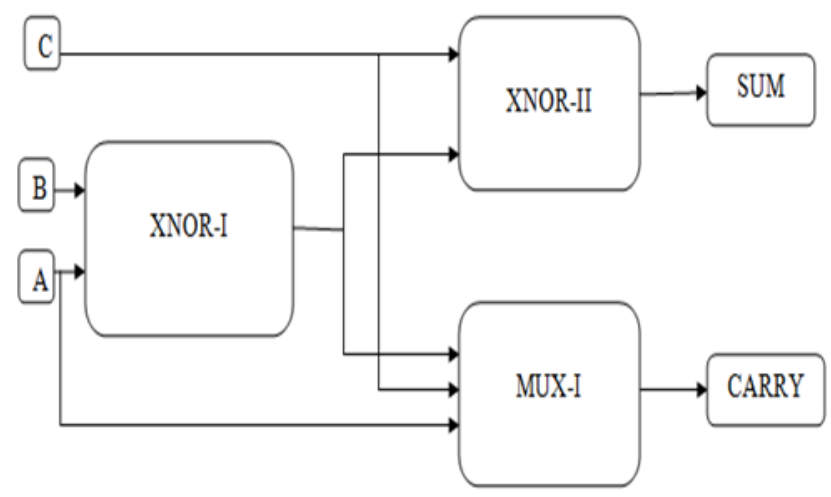

Fig.2.Block Diagram of proposed 10T-fulladder

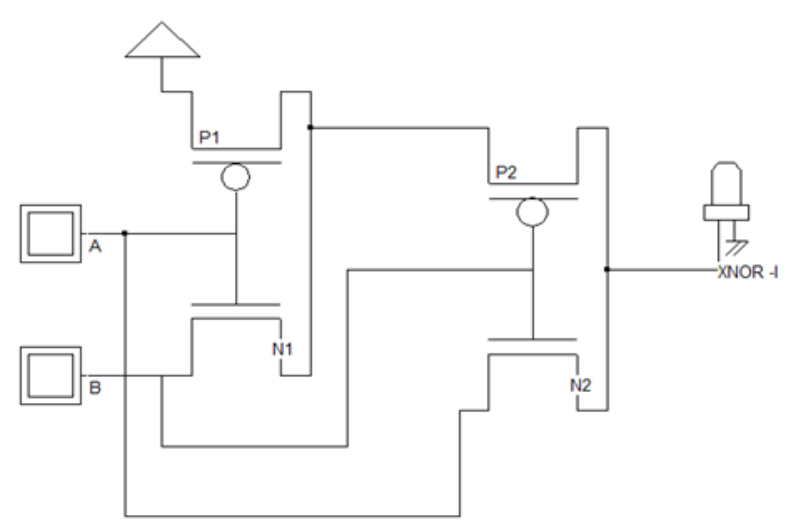

Figure 3: Proposed 10T-Full Adder model of XNOR-I MOS circuit

Shown in discern three while each the inputs are excessive, i.e. $A=1, b=1$ then the transistors $n 1, n 2$ are in on country wherein because the transistors $\mathrm{p} 1, \mathrm{p} 2$ are in off kingdom. Whilst each the inputs are low, i.e. $A=0, b=$ zero then the transistors $\mathrm{p} 1, \mathrm{p} 2$, are in on kingdom where because the transistors $\mathrm{n} 1, \mathrm{n} 2$ is in on nation. If the inputs are $\mathrm{a}=1$ and $b=0$ then the transistors $p 1, n 2$ is in off state and the transistors $\mathrm{p} 2, \mathrm{n} 1$ are in on state and if the inputs are a=zero and $b=1$ then the transistors $\mathrm{p} 1, \mathrm{n} 2$ is in on state and the transistors $\mathrm{p} 2, \mathrm{n} 1$ are in off nation. In the above two situations the inputs are complementary.

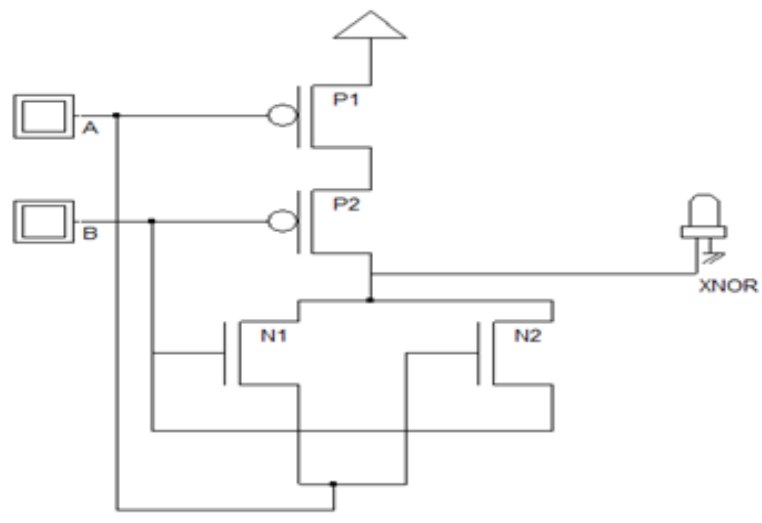

Figure 4: Proposed 10T-full adder model of XNOR-2 circuit

Appeared inside the Fig. 4 whilst two assets of data are excessive, for instance $\mathrm{A}=1, \mathrm{~B}=1$ then the transistors $\mathrm{N} 1, \mathrm{~N} 2$ are in $\mathrm{ON}$ kingdom where because the transistors $\mathrm{P} 1, \mathrm{P} 2$ are in OFF country. At the factor while each the facts assets are low, as an instance $\mathrm{A}=\mathrm{zero}, \mathrm{B}=0$ then the transistors $\mathrm{P} 1, \mathrm{P} 2$, are in ON state wherein as the transistors $\mathrm{N} 1, \mathrm{~N} 2$ is in $\mathrm{ON}$ kingdom. Be that as it is able to, two statistics assets are 0 $\mathrm{A}=1$ and $\mathrm{B}=0$ then the transistors $\mathrm{P} 1, \mathrm{~N} 1$ is in OFF state and the transistors $\mathrm{P} 2, \mathrm{~N} 2$ are in $\mathrm{ON}$ state and on the off risk that the statistics sources are $\mathrm{A}=\mathrm{zero}$ and $\mathrm{B}=1$, at that point the transistors $\mathrm{P} 1, \mathrm{~N} 1$ is in $\mathrm{ON}$ circumstance and the transistors $\mathrm{P} 2, \mathrm{~N} 2$ are in OFF situation.

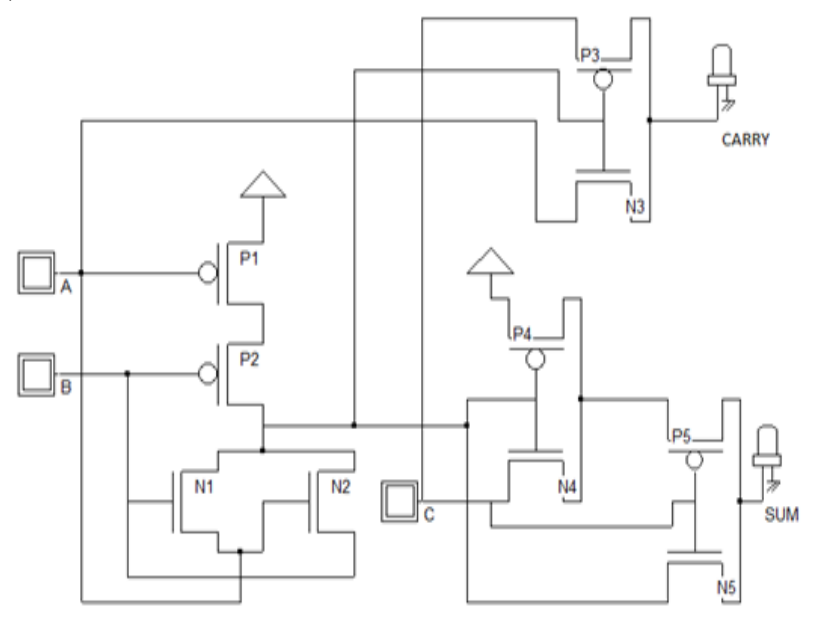

Figure 5: 10T-full adder model of total MOS circuit

\begin{tabular}{|c|c|c|c|c|c|c|c|c|}
\hline Transistor & 000 & 001 & 010 & 011 & 100 & 101 & 110 & 111 \\
\hline P1 & ON & ON & ON & ON & OFF & OFF & OFF & OFF \\
\hline P2 & ON & ON & OFF & OFF & ON & ON & OFF & OFF \\
\hline P3 & OFF & OFF & ON & ON & ON & ON & OFF & OFF \\
\hline P4 & ON & OFF & ON & OFF & OFF & OFF & ON & OFF \\
\hline P5 & OFF & OFF & ON & ON & ON & ON & OFF & OFF \\
\hline N1 & OFF & OFF & ON & ON & ON & OFF & ON & ON \\
\hline N2 & OFF & OFF & OFF & OFF & ON & ON & ON & ON \\
\hline N3 & ON & ON & OFF & OFF & OFF & OFF & ON & ON \\
\hline N4 & OFF & ON & OFF & ON & OFF & ON & OFF & ON \\
\hline N5 & ON & ON & OFF & OFF & OFF & OFF & ON & ON \\
\hline SUM & OFF & ON & ON & OFF & ON & OFF & OFF & ON \\
\hline CARRY & OFF & OFF & OFF & ON & OFF & ON & ON & ON \\
\hline
\end{tabular}

Table.1 functional verification table of full adder 


\section{PROPOSED MODIFIED CMOS ARRAY MULTIPLIER}

Cluster multiplier is remarkable due to its reliable shape. Multiplier circuit is constructed on flow and consist of strategies. every fragmentary item is made by means of the duplication of the multiplicand with one multiplier bit. The fragmentary gadgets are moved by using their bit requests and in a while protected. The expansion may be given everyday deliver engender snake. In show off engineering primarily based $n \times n$ bit multiplier makes use of cluster of AND doors can discern all of the aibj phrases on the equal time. The terms are summed via a diffusion of ' $n$ [n - 2]' complete adders and ' $n$ ' half adders. show off Multiplier offers more manage utilization just as best quantity of segments required, but postpone for this multiplier is more prominent. It moreover requires chip territory is multiplied for range transistor tally is increased exceptional to this CMOS showcase multiplier is low prudent. along these traces, it is a quick multiplier but equipment multifaceted nature is more distinguished.

The principles for cluster augmentation are,

- Networks have to have the equal measurements.

- Measurements of the consequent community are the equivalent as the 2 elevated lattices .

- Resultant additives are the consequences of referring to additives in the accelerated lattices as regarded in parent.

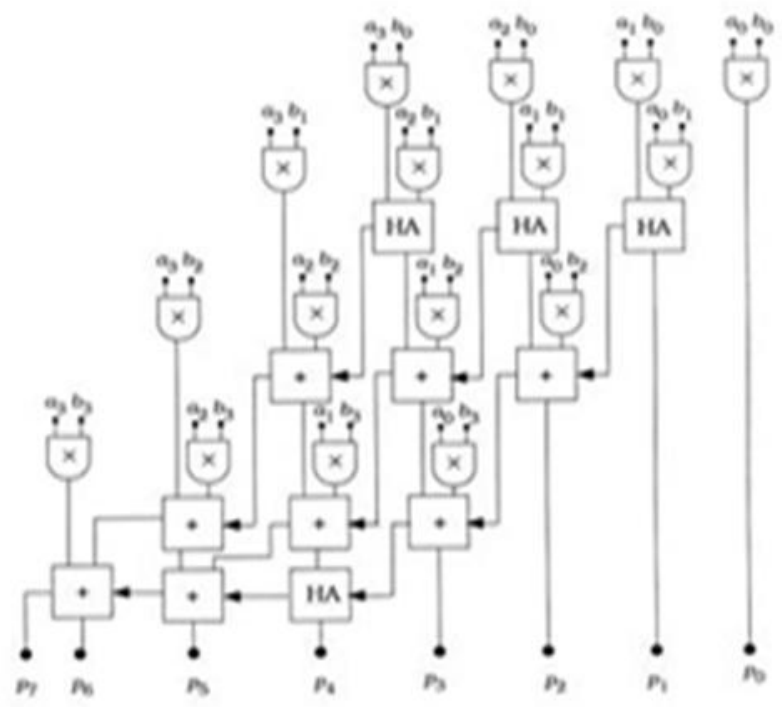

Figure 6: Array CMOS Architecture

\section{PROPOSED MODIFIED CMOS TREE MULTIPLIER}

A Wallace tree is a functioning approach for execution of a CMOS advanced circuit that increases whole numbers, constrained via Australian laptop Researcher Chris Wallace . The CMOS Wallace tree multiplier has a place segment strain multipliers circle of relatives. The number one guiding principle in those relations of multipliers is to accomplish partial item assembling by sequentially diminishing the amount of bits of statistics in each phase making use of full adders or $1 / 2$ adders.

The Wallace tree has 3 levels: degree 1: replica every piece utilizing AND doors and acquire the unfinished objects from the ones bits. As it's miles four $\times 4$ multiplier, all the 4 bits of multiplicand are elevated with four bits of multiplier acquiring 16 incomplete gadgets.

stage 2: expire the amount of fragmentary gadgets to two by means of of complete and $1 / 2$ snake cells.

stage three: collecting the wires in numbers, and consist of them with a proposed cell

\section{PERFORMANCE AND SIMULATION RESULTS}

Figure 7.full adder CMOS simulation results

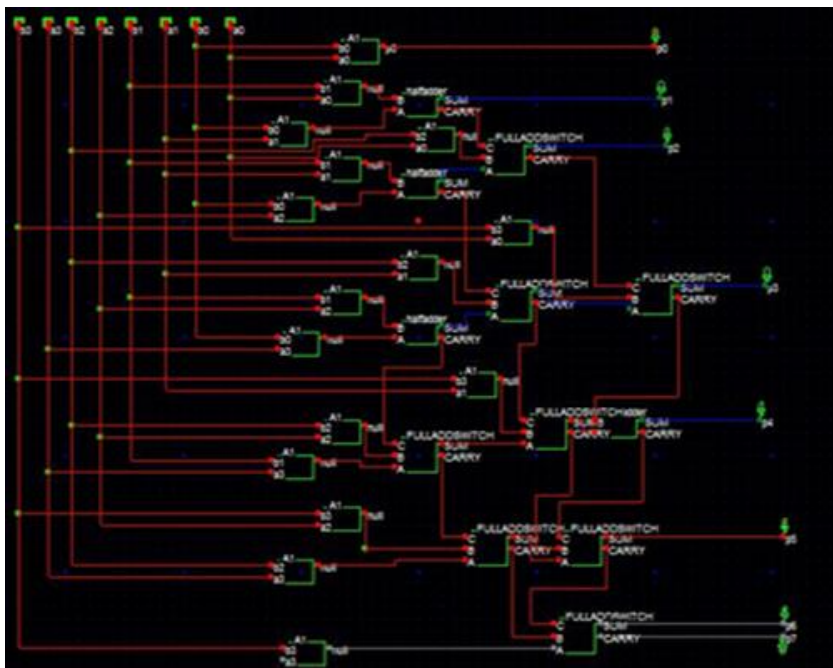

Fig.8 Proposed full adder with CMOS Array multiplier

\begin{tabular}{|c|c|c|c|c|}
\hline Path n & Symbol & Pin & Node & Delay (ns) \\
\hline 1 & Ighk1(13) & SUM(1) & 9 & 0.960 \\
\hline 2 & $\operatorname{monos}(8)$ & d(3) & 9 & 0.790 \\
\hline 3 & $\operatorname{monos}(8)$ & s(1) & 5 & 0.620 \\
\hline 4 & $\operatorname{monos}(3)$ & d(3) & 5 & 0.520 \\
\hline 5 & rmos(4) & d(3) & 5 & 0.520 \\
\hline 6 & penos(17) & d(3) & 5 & 0.620 \\
\hline 7 & penos(17) & s(1) & 3 & 0.100 \\
\hline 8 & pnos(2) & d(3) & 3 & 0.100 \\
\hline 9 & prnos(10) & d(3) & 9 & 0.960 \\
\hline 10 & penos(10) & s(1) & 8 & 0.790 \\
\hline
\end{tabular}

Fig.9 Delay report of CMOS Array multiplier 


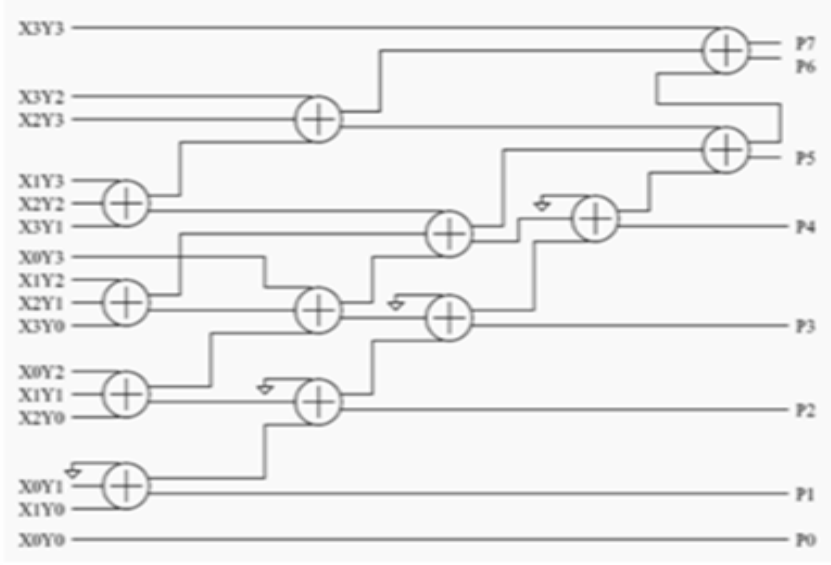

Fig.10 Block Diagram of CMOS Tree multiplier

\begin{tabular}{|l|l|l|}
\hline & 90 nm Technology & \\
\hline & $\begin{array}{l}\text { CMOS Array } \\
\text { multiplier }\end{array}$ & $\begin{array}{l}\text { Tree } \\
\text { Multiplier }\end{array}$ \\
\hline Power $(\mu \mathrm{w})$ & 161 & 121 \\
\hline Delay $(\mathrm{ns})$ & 4.9 & 6. \\
\hline PDP femito w/s & 644 & 726 \\
\hline Area $(\mu \mathrm{m} 2)$ & 7599 & 7313 \\
\hline & $65 \mathrm{~nm}$ technology & \\
\hline Power $(\mu \mathrm{w})$ & 37 & 21 \\
\hline Delay $(\mathrm{ns})$ & 3.9 & 6.9 \\
\hline PDP femito w/s & 144 & 144.9 \\
\hline Area $(\mu \mathrm{m} 2)$ & 3542 & 3266 \\
\hline
\end{tabular}

Table.2Comparison of multipliers

\section{CONCLUSION}

In this paper the proposed CMOS 10-t full snake model is used in arranging of low control cmos bunch and tree multiplier in $90 \mathrm{~nm}, 65 \mathrm{~nm}, 45 \mathrm{~nm}$ development. Additionally, the presentation of each tree and group multipliers are dismembered. The proposed $4 \times$ four CMOS Wallace tree multiplier has progressed execution to the volume manage dispersal; region and transistor comprise into extraordinary DSM development when stood out from display multiplier. The proposed four $\times$ four bunch multiplier has improved execution to the extent multiplication deferral and power delay aspect. As this paper shown by way of on plan of low manipulate multiplier circuits. The general connection reveals that tree multiplier has less control dispersal.

\section{REFERENCES}

1 M.B. Damle, Dr. S.S Limaye and M.G. Sonwani, "close to research of showcase Multiplier making use of distinct purpose patterns", IOSR Diary of building (IOSRJEN), Vol. 3, No. 5, pp. sixteen-22, may additionally 2013.

2 T. Sharma, Prof. B.P.Singh, okay.G.Sharma, N. Arora, "fast showcase Multipliers depending on 1-Piece complete Adders", in Int. J. of overdue styles in building and Innovation, Vol. 4, No. 4, pp.26-28, Nov 2010.

3 J.T.Yan and Z. W. Chen, "Low-manage multiplier shape with line and fragment bypassing", IEEE global SOC collecting, pp.227-230, 2009.

4 Ming-Chen Wen, Sying-Jyan Wang, and Yen-Nan Lin "Low energy Parallel Multiplier with section Bypassing" IEEE, 2005

5 Chin-long Wey and Ji-Fu Li "layout of Reconfigurable exhibit Multipliers and Multiplier-creditors" IEEE, 2004

6 DimitriosSoudris, Christian Piguet and Costas Goutis, "planning CMOS Circuits for Low strength", Kluwer Scholarly Distributer, Boston, 2002
7 B Parhami, "laptop number juggling - Calculations and gadget Designs", Oxford university Press, 2000.

8 R Zimmermann and $\mathrm{W}$ Fichtner, "Low manipulate justification styles: CMOS versus pass Transistor logic", IEEE Diary of robust state Circuits, Vol. 32, No. 7, pp.1079-1090, July 1997.

9 Tanner EDA Inc. 1988, consumer's manual, 2010.

10 T. Kuroda et al., "Diagram of Low-electricity usa Circuit techniques"

11 Bellaouar, An., and Elmasry, M. I., Low-strength superior VLSI Configuration: Circuits and Frameworks, Kluwer, Norwell, Mama, 1995.

12 Weste, and k. Eshraghian, "standards of CMOS VLSI layout", Addison-Weslet distributing organization, 1992

13 C S Wallace, "A recommendation for a fast Multiplier", IEEE Exchanges on digital desktops, EC-thirteen, pp. 